\section{Peripheral venoarterial extracorporeal membrane oxygenation for periprocedural Cardiogenic shock during interventional cardiology}

\author{
FERNANDO J. VERDUGO ${ }^{1,3, a}$, PABLA CATALDO ${ }^{1,2, a}$, JORGE SANDOVAL $^{1,2}$, \\ FERNANDO PINEDA ${ }^{1}$, CHRISTIAN DAUVERGNE ${ }^{1,2}$, \\ MANUEL DUARTE ${ }^{1,2, a}$, CAMILA BONTA $^{3}$, SEBASTIÁN ITURRA ${ }^{4}$, \\ GABRIEL OLIVARES ${ }^{4}$, MARCELO CONCHA $^{4}$, VÍCTOR ROSSEL ${ }^{1,2}$
}

\begin{abstract}
Background: Cardiogenic shock (CS) is uncommon in the cardiac catheterization laboratory (CCL) among patients undergoing coronary angiography. Periprocedural CS is more frequent in high-risk patients and in technically demanding procedures. Aim: To describe the clinical outcomes of patients who underwent peripheral venoarterial extracorporeal membrane oxygenation ( $p V A-E C M O)$ for CS associated with interventional cardiology procedures. Material and Methods: Review of clinical records of seven patients treated between January 2014 and October 2018. Results: $p V A-E C M O$ was implanted within 6 hours of the interventional cardiology procedure. All patients had coronary artery disease and one of them also had symptomatic severe aortic stenosis. One patient entered the CCL in cardiac arrest. Percutaneous coronary intervention (PCI) was performed in all patients; four patients underwent an emergency procedure and five patients experienced PCI complications. One patient undergoing transcatheter aortic valve replacement suffered acute severe aortic regurgitation. An intra-aortic balloon pump was inserted at the CCL in five patients. Six patients experienced cardiac arrest. Mean SAVE score was -4.3 and baseline lactate $55 \mathrm{mg} / \mathrm{dl}$. pVA-ECMO mean duration was $5 \pm 4$ days. Survival after both hospital discharge and 12 months of follow-up was $85.7 \%$ Regarding vascular access complications, we observed one access site hematoma and one episode of cannulation site bleeding requiring surgical repair. Conclusions: $p V A-E C M O$ should be considered in patients with periprocedural CS as a bridge to recovery. Its use was associated with improved clinical outcomes in this series.

(Rev Med Chile 2020; 148: 1295-1301)

Key words: Cardiac Catheterization; Extracorporeal Membrane Oxygenation; Shock, Cardiogenic.

\section{Oxigenación con membrana extracorpórea veno-arterial periférica para shock cardiogénico peri-procedimiento en cardiología intervencional}

Antecedentes: El shock cardiogénico (SC) es infrecuente en el laboratorio de cateterismo cardíaco (LCC) entre pacientes que son sometidos a coronariografía. El SC peri-procedimiento es más frecuente en pacientes de alto riesgo y

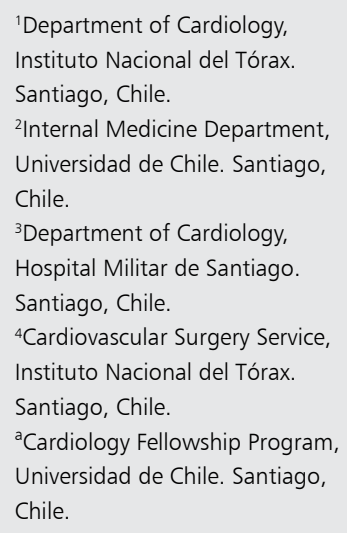

Sources of funding: None Disclosures: The authors report no conflicts of interest regarding this study.

Recibido el 19 de abril de 2020 , aceptado el 15 de julio de 2020.

Correspondence to:

Víctor Rossel, MD

Internal Medicine Department,

Universidad de Chile.

Avenida Salvador 486

Santiago, Chile.

vrossel@uchile.cl 
en procedimientos técnicamente complejos. Objetivos: Describir los resultados clínicos de pacientes que fueron conectados a oxigenación con membrana extracorpórea veno-arterial periférica (ECMO-VAp) por SC peri-procedimiento de cardiología intervencional. Material y Métodos: Revisión de fichas clínicas de siete pacientes tratados en nuestro centro desde enero de 2014 a octubre de 2018. Resultados: ECMO-VAp fue utilizado dentro de las primeras 6 horas del procedimiento. Todos los pacientes tenían enfermedad coronaria y uno de ellos tenía además estenosis aórtica severa. Un paciente ingresó al LCC en paro cardíaco. Una intervención coronaria percutánea (ICP) fue realizada en todos los pacientes; 4 se realizaron procedimientos de emergencia y 5 pacientes tuvieron complicaciones de la ICP. A un paciente se le realizó un reemplazo valvular aórtico percutáneo y desarrolló una insuficiencia valvular aórtica aguda severa. Se instaló un balón de contrapulsación en el LCC en 5 pacientes. Seis pacientes tuvieron un paro cardiorrespiratorio. El valor del score de SAVE fue de $-4,3$ y el lactato basal $55 \mathrm{mg} / \mathrm{dL}$. La duración media del ECMO-VAp fue $5 \pm 4$ días. La sobrevida al alta y a los 12 meses fue 85,7\%. Como complicaciones del sitio de acceso vascular se observaron 1 hematoma y un episodio de sangrado que requirió reparación quirúrgica. Conclusiones: ECMO-VAp debería ser considerado en pacientes con SC peri-procedimiento como un puente a recuperación; su utilización estuvo asociada con mejoría de resultados clínicos en esta serie.

Palabras clave: Cateterismo; Choque Cardiogénico; Oxigenación por membrana extracorpórea.

\section{Introduction}

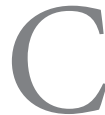
ardiogenic shock (CS) is uncommon in the cardiac catheterization laboratory $(\mathrm{CCL})$, with an incidence of $0.24 \%-0.47 \%$ among patients undergoing coronary angiography ${ }^{1,2}$. Periprocedural CS is more frequent in high-risk patients due to baseline cardiovascular disease and the technically-demanding procedures performed. Observational studies reveal an incidence of 3.5\%$4.3 \%$ in patients with acute coronary syndromes ${ }^{3,4}$, and a periprocedural CS incidence of $1.6 \%$ has been reported in intermediate-risk patients undergoing transcatheter aortic valve replacement $(\text { TAVR })^{5}$. Despite advances in percutaneous interventions and hemodynamic support, the prognosis for CS remains poor, with short-term mortality rates of $40 \%-60 \% \%^{2,6,7}$.

Short-term mechanical circulatory support (MCS) aims to improve hemodynamic status and tissue perfusion to achieve recovery or provide time to establish a prognosis and definitive treatment. Consensus statements suggest that short-term MCS may be considered in patients experiencing periprocedural $\mathrm{CS}^{8,9}$. Among MCS devices, peripheral venoarterial extracorporeal membrane oxygenation (VA-ECMO) has several advantages, including easy installation, highly effective hemodynamic and respiratory support, compatibility with therapeutic hypothermia and low cost $^{8}$.

This report describes the clinical outcomes of patients undergoing peripheral VA-ECMO for CS linked to interventional cardiology procedures at our center.

\section{Patients and Methods}

We conducted a retrospective observational study at a tertiary care center. The study included adult patients ( $\geq 18$ years) undergoing interventional cardiology procedures who developed periprocedural CS and underwent peripheral VA-ECMO from January 2014 to October 2018. The study was approved by the Chilean Eastern Metropolitan Health Service ethics committee.

CS was defined according to the Society for Cardiovascular Angiography and Interventions (SCAI) consensus statement ${ }^{6,7}$. Patients were retrospectively categorized into one of five CS stages at CCL admission, prior to VA-ECMO: At risk (A), Beginning (B), Classic (C), Deteriorating (D), Extremis or Refractory (E). The subscript " $A$ " at any stage signifies cardiac arrest. 
Indications for peripheral VA-ECMO were at the discretion of the HEART team. Peripheral VA-ECMO was implanted by cardiac surgeons in the CCL or operating room (OR) within 6 hours of the interventional cardiology procedure in the case of deteriorating or refractory CS. Cannulation of femoral vessels was performed using a modified Seldinger technique, with 15-22 Fr arterial and 21-29 Fr venous cannulae, according to surgeon preference. Patients were postoperatively admitted to the ICU and treated per intensive care standards. VA-ECMO was removed in the OR by cardiac surgeons.

Clinical records were reviewed to record demographics, vital signs, laboratory data, clinical outcomes, and procedures performed during the hospital stay. Estimated in-hospital survival was assessed with the modified survival after VA-ECMO (SAVE) score ${ }^{10}$. The Chilean Civil Registry database was reviewed for survival statistics.

\section{Statistics}

Continuous data are expressed as mean \pm standard deviation or median and categorical data as absolute number and percentage.

\section{Results}

Peripheral VA-ECMO was implanted in seven patients. Baseline characteristics are shown in Table 1 . Mean age was $56.9 \pm 16.9$ years; $71.4 \%$ were male; $57.1 \%$ had hypertension; $42.9 \%$ had dyslipidemia; $42.9 \%$ had prior tobacco consumption. All patients had coronary artery disease. One patient had symptomatic severe aortic valve stenosis and severe stenosis in the middle segment of the left descending coronary artery and proximal segment of the circumflex artery, considered a candidate for elective TAVR and PCI after assessment by the HEART team. One patient entered the CCL in cardiac arrest (SCAI E $\mathrm{A}_{\mathrm{A}}$ ); six patients $(85.7 \%)$ were at risk for CS (SCAI A). Percutaneous coronary intervention (PCI) was performed in all patients. Four patients $(57.1 \%)$ had emergency PCI due to ST-elevation myocardial infarction. Two patients $(28.6 \%)$ with chronic coronary syndrome were scheduled for elective PCI for left main coronary artery bifurcation disease. Five patients (71.4\%) experienced PCI complications: one dissection at the distal stent edge; one abrupt left main coronary artery closure; one coronary perforation managed with a covered stent with later intraprocedural stent thrombosis; and two intraprocedural stent thromboses. One patient undergoing TAVR suffered acute severe aortic regurgitation. All complications were associated with hemodynamic instability and managed percutaneously during the procedure, achieving revascularization of target vessels or TAVR implant accordingly.

Upon hemodynamic deterioration, patients received vasopressor/inotropic medications, with a median of two drugs. An intra-aortic balloon pump (IABP) was inserted in the CCL in five patients $(71.4 \%)$. Six patients $(85.7 \%)$ experienced cardiac arrest, with a cardiopulmonary resuscitation time of $23 \pm 12$ minutes. Peripheral VA-ECMO was implanted in the CCL in five patients (71.4\%); in two cases as extracorporeal life support and in the others due to CS. Two patients $(28.6 \%)$ completed PCI under VA-ECMO. Two patients $(28.6 \%)$ had peripheral VA-ECMO implanted in the OR. Mean SAVE score was $-4.3 \pm 4.9$ (median -5); baseline lactate $55 \pm 36 \mathrm{mg} / \mathrm{dl}$ (median $36 \mathrm{mg} /$ $\mathrm{dl}$ ); and modified SAVE score $6.4 \pm 10.5$ (median 7). VA-ECMO pump flow was $3.7 \pm 0.6 \mathrm{~L} / \mathrm{min}$.

Table 2 summarizes clinical outcomes and complications. Peripheral VA-ECMO duration was $5 \pm 4$ days. Concomitant IABP was used in three patients $(42.8 \%)$. At initial echocardiographic assessment, mean left ventricular ejection fraction was $38 \% \pm 11 \%$. Lactate clearance returned to normal values within 48 hours in six patients $(85.7 \%)$ (Figure 1). Median invasive mechanical ventilation time, ICU and hospital stays were 14,18 and 26 days, respectively. Survival to both hospital discharge and 12 months of follow-up was $85.7 \%$. The deceased patient developed multi-organ failure and severe hypoxic-ischemic encephalopathy and was declared brain dead at 48 hours from VA-ECMO implant. One patient developed pulmonary edema refractory to adjustments in therapy, requiring bridging to central MCS (CentriMag $^{\mathrm{TM}}$ ) and transplant (performed after 86 days). The other patient with pulmonary edema was successfully weaned. Five patients $(71.4 \%)$ had ventilator-associated pneumonia. Regarding vascular access complications, we observed one access site hematoma and one episode of cannulation site bleeding requiring surgical repair. Two patients required hemodialysis $(28.6 \%)$. 
Table 1. Baseline characteristics and procedural details of patients with periprocedural cardiogenic shock undergoing emergency peripheral VA-ECMO implant

\begin{tabular}{|c|c|c|c|c|c|c|c|}
\hline Patient & 1 & 2 & 3 & 4 & 5 & 6 & 7 \\
\hline Age (years) & 51 & 68 & 37 & 40 & 86 & 59 & 59 \\
\hline Gender & Male & Male & Male & Female & Male & Female & Male \\
\hline BMI (kg/m2) & 27.9 & 31.9 & 24.2 & 24.2 & 25.5 & 21.2 & 25.7 \\
\hline Hypertension & Yes & Yes & No & No & Yes & No & Yes \\
\hline Diabetes & No & No & Yes & No & No & No & No \\
\hline Dyslipidemia & Yes & Yes & No & No & No & No & Yes \\
\hline Tobacco use & No & No & No & Yes & No & Yes & Yes \\
\hline Diagnosis pre-CCL & STEMI & CCS & STEMI & STEMI & SAVS & STEMI & CCS \\
\hline CS stage pre-CCL & $A$ & A & $E_{A}$ & A & A & A & A \\
\hline PCI performed & Yes & Yes & Yes & Yes & Yes & Yes & Yes \\
\hline PCI-treated vessel & LAD & LMCA & LAD & RCA & $\mathrm{LAD} / \mathrm{CX}$ & $\mathrm{LAD} / \mathrm{CX}$ & LMCA \\
\hline PCl complication & Yes & Yes & No & Yes & No & Yes & Yes \\
\hline TAVR performed & No & No & No & No & Yes & No & No \\
\hline IABP pre-ECMO & Yes & Yes & Yes & No & No & Yes & Yes \\
\hline CS stage pre-ECMO & $D_{A}$ & $E_{A}$ & $E_{A}$ & $E_{A}$ & $\mathrm{D}_{\mathrm{A}}$ & $\mathrm{D}$ & $\mathrm{D}_{\mathrm{A}}$ \\
\hline CPR time (minutes) & 10 & 40 & 20 & 30 & 30 & 0 & 10 \\
\hline ECMO implant unit & $\mathrm{CCL}$ & $\mathrm{CCL}$ & OR & $\mathrm{CCL}$ & $\mathrm{CCL}$ & $\mathrm{CCL}$ & OR \\
\hline ECLS & No & Yes & No & Yes & No & No & No \\
\hline SAVE score & -5 & -8 & -10 & 0 & -9 & 2 & 0 \\
\hline Lactate (mg/dl) & 123 & 36 & 78 & 20 & 33 & 59 & 36 \\
\hline Modified SAVE score & -5 & 7 & -10 & 15 & 6 & 17 & 15 \\
\hline ECMO flow (lpm) & 4.2 & 2.9 & 3.7 & 4.3 & 2.8 & 3.7 & 4.0 \\
\hline
\end{tabular}

BMI: Body mass index. CCL: Cardiac catheterization laboratory. STEMI: ST-elevation myocardial infarction. CCS: Chronic coronary syndrome. SAVS: Severe aortic valve stenosis. CS: Cardiogenic shock. PCl: Percutaneous coronary intervention. LAD: Left anterior descending artery. LMCA: Left main coronary artery. RCA: Right coronary artery. CX: Circumflex artery. TAVR: Transcatheter aortic valve replacement. IABP: Intra-aortic balloon pump. ECMO: Extracorporeal membrane oxigenation. CPR: Cardiopulmonary resuscitation. OR: Operating room. ECLS: Extracorporeal life support. Ipm: Liters per minute (at initiation).

\section{Discussion}

We describe an initial experience with peripheral VA-ECMO for periprocedural CS in a heterogeneous population undergoing interventional cardiology procedures. The use of peripheral VA-ECMO was effective in restoring systemic perfusion, allowing for completion of procedures; bridge to recovery, transplantation or decision and overall improved clinical outcomes.

Patients with periprocedural CS subjected to peripheral VA-ECMO had in-hospital and 12 -month survival rates of $85.7 \%$ in our series.
Prior studies in patients undergoing interventional cardiology procedures have described lower in-hospital survival rates despite implementation of VA-ECMO programs in the CCL. In patients with acute myocardial infarction experiencing refractory CS, several cases series reported survival rates of $22 \%-65 \%$ after peripheral VA-ECMO ${ }^{11-17}$. In patients suffering hemodynamic complications during TAVR, rescue VA-ECMO support produced in-hospital survival rates of $44 \%-75 \%{ }^{17-20}$. Differences in survival might be partially explained by variability in definitions of refractory CS and associated multi-organic failure. This problem 
Table 2. Evolution, clinical outcomes and complications of patients with periprocedural cardiogenic shock undergoing peripheral VA-ECMO implant

\begin{tabular}{|llllllll|}
\hline Patient & $\mathbf{1}$ & $\mathbf{2}$ & $\mathbf{3}$ & $\mathbf{4}$ & $\mathbf{5}$ & $\mathbf{6}$ & $\mathbf{7}$ \\
\hline ECMO duration (days) & 7 & 2 & 2 & 12 & 2 & 4 & 5 \\
\hline IABP duration (days) & 0 & 3 & 2 & 0 & 0 & 2 & 0 \\
\hline LVEF (\%) & 40 & 56 & 35 & 40 & 46 & 25 & 27 \\
\hline IMV duration (days) & 36 & 3 & 2 & 15 & 4 & 14 & 30 \\
\hline ICU stay (days) & 40 & 5 & 2 & 15 & 4 & 14 & 98 \\
\hline Hospital stay (days) & 56 & 8 & 2 & 31 & 11 & 26 & 98 \\
\hline Pulmonary edema & Yes & No & No & No & No & No & Yes \\
\hline Hospital-acquired infection & Yes & No & No & Yes & Yes & Yes & Yes \\
\hline Neurologic complication & No & No & Yes & No & No & No & No \\
\hline Vascular complication & Yes & No & No & Yes & No & No & No \\
\hline Acute kidney injury & Yes & No & Yes & No & No & No & Yes \\
\hline Hemodialysis & Yes & No & Yes & No & No & No & No \\
\hline Outcome & CR & CR & Death & CR & CR & CR & HT \\
\hline In-hospital survival & Yes & Yes & No & Yes & Yes & Yes & Yes \\
\hline 12-month survival & Yes & Yes & No & Yes & Yes & Yes & Yes \\
\hline
\end{tabular}

ECMO: Extracorporeal membrane oxigenation. IABP: Intra-aortic balloon pump. LVEF: Left ventricular ejection fraction (by Simpson's biplane). IMV: Invasive mechanical ventilation. ICU: Intensive care unit. CR: Cardiac recovery. HT: Heart transplant.



Figure 1. Evolution of lactate levels during the first 48 hours of hemodynamic support with peripheral VA-ECMO. Continuous grey lines show patients achieving survival to discharge $(n=6)$. Continuous black line marks the deceased patient $(n=1)$. Dashed black line marks the normal upper limit of lactate at $19.8 \mathrm{mg} / \mathrm{dl}$. could be solved by implementing the SCAI CS classification ${ }^{6}$. Jentzer et al. validated the risk stratification capacity of SCAI CS stages in patients admitted to a cardiac ICU $(\mathrm{n}=10,004)$, showing good prognostic discrimination for in-hospital mortality (AUC 0.78$)^{7}$. Extrapolating their results, our expected in-hospital mortality for a median SCAI CS stage D would have been approximately $60 \%$.

Lactate prior to VA-ECMO seems to be valuable for clinical outcome prediction. Series of patients with acute myocardial infarction experiencing refractory CS with lactate levels over $70 \mathrm{mg} / \mathrm{dl}$ describe in-hospital survival rates of $35 \%-50 \%$ after VA-ECMO ${ }^{10,14-17}$. The modified SAVE score, which incorporates lactate level at a cutoff of $>75 \mathrm{mg} / \mathrm{dl}$, has enhanced prediction of adverse outcomes in patients with refractory CS undergoing VA-ECMO $(\mathrm{AUC}=0.84)^{10}$. Our expected survival according to this score was $52 \%$, lower than observed results. The modified SAVE score was validated in patients with lactate between 56 and $125 \mathrm{mg} / \mathrm{dl}$, perhaps loosing accuracy in deteriorating CS. A study by Hryniewicz et al. in patients with refractory CS reported a mean of 3.4 
vasoactive agents, median lactate of $39.6 \mathrm{mg} / \mathrm{dl}$ and in-hospital survival of $65 \%$ after VA-ECMO ${ }^{12}$. Our series was similar in terms of baseline characteristics and lactate levels, but with a mean of only 2.3 vasoactive medications and more favorable outcomes. We concur with Hryniewicz et al. that early VA-ECMO implantation in patients with refractory CS, prior to higher lactate increases, could improve outcomes.

All patients experienced at least one complication associated with peripheral VA-ECMO. In terms of peripheral VA-ECMO complications in the context of periprocedural CS, previous studies report vascular complications requiring surgery in $11 \%-37 \%$, bleeding related to ECMO in $8 \%-34 \%$, neurologic complications in $9 \%-32 \%$ and dialysis requirement in 30\%$46 \%$ of patients. Our results were similar for the aforementioned complications. Interestingly, installation by experienced operators in the CCL does not seem to produce a higher rate of vascular complications as compared to surgical implantation in the $\mathrm{OR}^{11}$.

\section{Limitations}

Study limitations include the small number of patients and retrospective design, which preclude further analysis. There was inconsistent availability of some variables, including time to pump installation and transfusions. Comparisons with other types of MCS were not feasible, given the concomitant IABP and lack of availability of other devices.

\section{Conclusion}

Peripheral VA-ECMO was associated with improved clinical outcomes in this series. This procedure should be considered in patients with periprocedural CS as a bridge to recovery or decision. Prospective multicenter registries evaluating the safety, efficacy or futility of MCS in different settings are of significant interest.

\section{References}

1. Dehmer GJ, Weaver D, Roe MT, Milford-Beland S, Fitzgerald S, Hermann A, et al. A contemporary view of diagnostic cardiac catheterization and percutaneous co- ronary intervention in the United States: A report from the CathPCI registry of the national cardiovascular data registry, 2010 through june 2011. J Am Coll Cardiol. 2012; 60 (20): 2017-31.

2. Weipert KF, Bauer T, Nef HM, Hochadel M, Weidinger $\mathrm{F}$, Gitt AK, et al. Incidence and outcome of peri-procedural cardiogenic shock: results from the international Euro Heart Survey PCI registry. Eur Hear J Acute Cardiovasc Care. 2019; 9 (2): 120-73.

3. De Luca L, Olivari Z, Farina A, Gonzini L, Lucci D, Di Chiara A, et al. Temporal trends in the epidemiology, management, and outcome of patients with cardiogenic shock complicating acute coronary syndromes. Eur J Heart Fail. 2015; 17 (11): 1124-32.

4. Hunziker L, Radovanovic D, Jeger R, Pedrazzini G, Cuculi F, Urban P, et al. Twenty-year trends in the incidence and outcome of cardiogenic shock in AMIS plus registry. Circ Cardiovasc Interv. 2019; 12 (4): e007293.

5. Tam DY, Vo TX, Wijeysundera HC, Ko DT, Rocha RV, Friedrich J, et al. Transcatheter vs surgical aortic valve replacement for aortic stenosis in low-intermediate risk patients: A Meta-analysis. Can J Cardiol. 2017; 33 (9): 1171-9.

6. Baran DA, Grines CL, Bailey S, Burkhoff D, Hall SA, Henry TD, et al. SCAI clinical expert consensus statement on the classification of cardiogenic shock. Catheter Cardiovasc Interv. 2019; 94 (1): 29-37.

7. Jentzer JC, van Diepen S, Barsness GW, Henry TD, Menon V, Rihal CS, et al. Cardiogenic Shock Classification to Predict Mortality in the Cardiac Intensive Care Unit. J Am Coll Cardiol. 2019; 74 (17): 2117-28.

8. Rihal CS, Naidu SS, Givertz MM, Szeto WY, Burke JA, Kapur NK, et al. 2015 SCAI/ACC/HFSA/STS clinical expert consensus statement on the use of percutaneous mechanical circulatory support devices in cardiovascular care. J Am Coll Cardiol. 2015; 65 (19): e7-26.

9. Rossel V, Díaz R, Merello L, Santander EA, Stockins A, Olivares G. Recommendations for the management of patients with short-term mechanical circulatory assistance. Rev Med Chile 2018; 146 (1): 96-106.

10. Chen WC, Huang KY, Yao CW, Wu CF, Liang SJ, Li $\mathrm{CH}$, et al. The modified SAVE score: Predicting survival using urgent veno-arterial extracorporeal membrane oxygenation within 24 hours of arrival at the emergency department. Crit Care. 2016; 20 (1): 336.

11. Goslar T, Knafelj R, Radsel P, Fister M, Golicnik A, Steblovnik K, et al. Emergency percutaneous implantation of veno-arterial extracorporeal membrane oxygenation in the catheterisation laboratory. EuroIntervention. 2016; 12 (12): 1465-72. 
12. Hryniewicz K, Sandoval Y, Samara M, Bennett M, Cabuay B, Chávez IJ, et al. Percutaneous venoarterial extracorporeal membrane oxygenation for refractory cardiogenic shock is associated with improved shortand long-term survival. ASAIO J. 2016; 62 (4): 397-402.

13. Gass A, Palaniswamy C, Aronow WS, Kolte D, Khera S, Ahmad $\mathrm{H}$, et al. Peripheral venoarterial extracorporeal membrane oxygenation in combination with intra-aortic balloon counterpulsation in patients with cardiovascular compromise. Cardiology. 2014; 129 (3): 137-43.

14. Parr CJ, Sharma R, Arora RC, Singal R, Hiebert B, Minhas K. Outcomes of extracorporeal membrane oxygenation support in the cardiac catheterization laboratory. Catheter Cardiovasc Interv. 2019; doi: 10.1002/ ccd.28492.

15. Guenther S, Theiss HD, Fischer M, Sattler S, Peterss S, Born F, et al. Percutaneous extracorporeal life support for patients in therapy refractory cardiogenic shock: initial results of an interdisciplinary team. Interact Cardiovasc Thorac Surg. 2014; 18 (3): 283-91.

16. Ternus B, Jentzer J, Bohman K, Barsness G, Schears G, Rihal C, et al. Initiation of extracorporeal membrane oxygenation in the cardiac catheterization laboratory:
The Mayo Clinic Experience. J Invasive Cardiol. 2019; 32 (2): 64-9.

17. Arlt M, Philipp A, Voelkel S, Schopka S, Husser O, Hengstenberg C, et al. Early experiences with miniaturized extracorporeal life-support in the catheterization laboratory. Eur J Cardio-Thoracic Surg. 2012; 42 (5): 858-63.

18. Banjac I, Petrovic M, Akay MH, Janowiak LM, Radovancevic R, Nathan S, et al. Extracorporeal membrane oxygenation as a procedural rescue strategy for transcatheter aortic valve replacement cardiac complications. ASAIO J. 2016; 62 (1): e1-4.

19. Trenkwalder T, Pellegrini C, Holzamer A, Philipp A, Rheude T, Michel J, et al. Emergency extracorporeal membrane oxygenation in transcatheter aortic valve implantation: A two-center experience of incidence, outcome and temporal trends from 2010 to 2015 . Catheter Cardiovasc Interv. 2018; 92 (1): 149-56.

20. Husser O, Holzamer A, Philipp A, Nunez J, Bodi V, Müller T, et al. Emergency and prophylactic use of miniaturized veno-arterial extracorporeal membrane oxygenation in transcatheter aortic valve implantation. Catheter Cardiovasc Interv. 2013; 82 (4): 542-51. 